\title{
Six Classic Distribution Paradigms for Global Marketing Channel Strategy*
}

\author{
Bert Rosenbloom ${ }^{* *}$
}

\begin{abstract}
Global marketing has become an established fact of life for more and more businesses. Along with the large multinational corporations that have been operating on a global scale for decades, many middle market or even relatively small firms have already or will soon need to enter the global marketplace to enhance their long-term viability (Czinkota et al 1995). The growth of Internetbased e-commerce has accelerated this global trend..

Marketing channels which provide the institutional structure that connects firms to the markets they serve have not escaped this global environment. In today's world, marketing channel structure and strategy must be formulated in the context of globalization

The six distribution channel paradigms discussed are characterized as 'classic' because they have all appeared in the scholarly literature associated with marketing channels and distribution systems for many years and in some cases many decades.
\end{abstract}

Keywords: Global Marketing; Retail Channel; Disintermediation; Marketing Channel

\section{Some Classic Distribution Paradigms}

As we move close to the end of the first decade of the twenty-first century, global marketing has become an established fact of life for more and more businesses (Cateora and Graham 2007). Along with the large multinational corporations that have been operating on a global scale for decades, many middle market or even relatively small firms have already or will soon need to enter the global marketplace to enhance their long-term viability (Czinkota et al 1995). The growth of Internet-based e-commerce has accelerated this global trend by providing the

\footnotetext{
* Invited Article

** Rauth Chair Professor of Marketing Management, Drexel University, Philadelphia (rosenblb@drexel.edu)
} 
capacity to efficiently link firms from around the globe in a vast electronic marketplace (Kalakota and Whinston 1996).

Marketing channels which provide the institutional structure that connects firms to the markets they serve have not escaped this global environment. On the contrary, in today's world, marketing channel structure and strategy must be formulated in the context of globalization (Rosenbloom and Larsen 2008). Thus, managers responsible for developing and managing the distribution channels that make products and services available to literally billions of customers around the world face a more complex challenge than the previous generation of channel managers. Not only do today's channel managers need to think globally, but they must also act locally in terms of providing the appropriate array of channels desired by heterogeneous markets all over the world (Rosenbloom 2004).

The purpose of this article is to examine several classic marketing channel paradigms from the distribution channels literature in terms of the implications they offer for enhancing global channel management.

The six distribution channel paradigms discussed below are characterized here as 'classic' because they have all appeared in the scholarly literature associated with marketing channels and distribution systems for many years and in some cases many decades. Further, they have all stood the test of time in terms of providing a conceptual base for gaining insight into distribution channel developments, trends, and issues.

\section{Disintermediation Paradigm}

Although the term 'disintermediation' is of relatively recent vintage, the concept itself has been around for literally thousands of years dating back to ancient Greece and Rome (Beckman et al. 1959). This concept is, of course, that of eliminating middlemen from channels of distribution. Either explicitly or implicitly, middlemen are viewed as superfluous institutions, even 'parasites,' that do nothing but increase the costs of products as they move from producers to consumers. Thus, the argument goes, middlemen should be gotten rid of or, to use the more modern term, disintermediated from the channel. The arrival of the Internet as the technological base for online electronic commerce at the close of the twentieth century reinvigorated the disintermediation paradigm (Rosenbloom 2002). With the Internet providing the capability to create a giant, global electronic marketplace where vast numbers of producers and consumers could be linked directly to each other, who would need middlemen?

But even in the age of high-tech electronic commerce, the disintermediation paradigm did not unfold at anywhere near the pace or scope predicted. Middlemen at the retail and wholesale levels as well as a myriad of agents and brokers continue to operate across a vast spectrum of distribution channels. Why do so many middlemen continue to exist even in the face of the awesome power of Internetbased electronic commerce? The answer can be found in basic economics. Specifically, middlemen or intermediaries emerge in distribution channels because they are able to perform distribution tasks necessary to make products and services available to final customers more efficiently then producers or consumers. In effect, 
intermediaries are often the low cost 'producers' of distribution services because as specialists in the performance of such services they enjoy the benefits of economies of scale and economies of scope (Stigler 1951). Over the long run, if intermediaries are not able to fulfil this role, they will disappear from the marketing channel. However, in most cases, the distribution tasks they perform will not be taken over by producers and consumers but by other types of intermediaries that emerge in the channel that are able to provide distribution services more efficiently (Anderson and Anderson 2002). The corner grocery store being replaced by the supermarket, the hardware stores by home centers, and bookstores by online retailer Amazon.com are typical examples. In recent years, this type of metamorphosis in distribution channels has been referred to as reintermediation - a reconfiguration of middlemen in distribution channels rather than their elimination of intermediaries from distribution channels.

From the standpoint of global marketing channel strategy, the disintermediation paradigm should not be ignored but neither should it be taken at face value. That is, the wide array of intermediaries or middlemen from traditional merchant wholesalers and retailers as well as export merchants, manufacturer's export agents, resident buyers, export commission houses and numerous others are not likely to be 'disintermediated' anytime soon. Rather, a reconfiguration or reintermediation based on the laws of economics is the more likely outcome for global marketing channel structures. Consequently, channel managers operating in the global arena, rather than focusing on eliminating intermediarie, should instead attempt to design marketing channels that incorporate an optimum mix of intermediaries capable of enhancing channel efficiency.

\section{Functional Shifting Paradigm}

There is a famous saying that is probably as old as the marketing discipline itself: 'You can eliminate the middleman but not the functions he performs.' This is about as close to an 'axiom' as one can find in the marketing literature. The idea that functions or distribution tasks that need to be performed to consummate transactions between buyers and sellers cannot be eliminated from the distribution channel but only shifted within it is as true today as it ever was (Weld 1917). It is, in effect, the marketing discipline's version of the 'conservation of matter' associated with the physical sciences. Marketing functions such as transportation, storage, risk-taking, order processing, buying, selling and numerous others can be transformed in many ways, but ultimately they still must be performed. Even the cutting edge online technology used by Amazon.com involves the performance of marketing functions. Thus, the real question with regard to the performance of marketing functions or distribution tasks is not whether they need to be performed but who should perform them (Mallen 1973). In other words, how and on what basis should the distribution tasks be allocated among channel participants?

In today's global markets where distribution channels commonly reach beyond any one nation's borders and frequently extend to operate in many countries, the concept of functional shifting is as relevant to designing effective and efficient channel structures as ever. Channel managers attempting to make products and 
services available to diverse and distant global markets need channel structure, and most probably multiple channel structures, to reach their customers (Rosenbloom 2007). To do so, the channel manager needs to focus on three core questions associated with the functional shifting paradigm:

1. What is the most economical channel structure(s) for performing the distribution tasks?

2. What degree of control is desired by the channel manager's firm?

3. Is distribution channel strategy a core competency of the channel manager's firm?

Economics of Channel Structure. Even with the advent of the Internet and the emergence of global markets, the laws of economics have not been repealed. The channel strategies and structures used to reach global markets must be cost efficient in order to be viable. In many cases, Internet-based online technologies can dramatically reduce the cost of distribution, especially for products that can be digitized such as written material, music, and financial services. For other products that are heavy and bulky or have low unit value, online channel structure may offer far less cost efficiency. So, those managers responsible for designing global marketing channels need to avoid the temptation of thinking that 'the Internet changes everything.' It has not. Economic feasibility is still the foundation on which channel structure is built.

Control and Channel Structure. Another old marketing 'axiom' or heuristic is: 'the longer the channel the less the degree of control provided to the producer or manufacturer and vice versa.' So, if the channel manager is seeking maximum control over how its products are brought to market, the channel structure should be as short as possible, with the shortest channel structure being direct distribution from producer to final consumer. On the other hand, if control is not an important consideration, long channels utilizing numerous intermediaries that enable the producer to reach global markets with minimal investment and low cost may be the optimal channel choice. But here again, just as with economic considerations, the basic issue of control does not disappear just because powerful online technologies are available and distribution occurs on a global scale. If how products are made available to final customers can affect brand equity, product positioning, or customer service, who controls the channel of distribution can be crucial to successful global marketing.

Core Competency and Channel Structure. The strategic management and planning literature has focused on the concept of core competency for several decades (Prahalad and Hamel 1990). There is good reason for this. A firm's long term viability can be and usually is closely tied to what it can do best. If a firm steps outside of its areas of core competency and ventures into those where it has less expertise, its competitiveness can suffer because it is not operating from its position of maximum strength.

In the area of channel strategy and structure, if the firm does not have the requisite competency to handle distribution tasks in today's global environment, it 
may be to its advantage to shift them to channel participants that do have such expertise.

\section{Channel Flows Paradigm}

Over a half century ago, marketing scholars began describing marketing channels as a system of flows (Vail et al 1952). Eight flows were described:

1. Product flow

2. Ownership flow

3. Promotion flow

4. Negotiation flow

5. Financing flow

6. Risk flow

7. Ordering flow

8. Payment flow

All of these flows operate through the institutional structure of marketing which includes numerous intermediaries such as retailers, wholesalers, and many different types of agents and brokers. Viewed from the perspective of these eight flows, the task of channel management becomes essentially one of establishing, coordinating, and monitoring these flows which connect sellers and buyers together.

While the concept of channel flows has become a well accepted paradigm in the marketing channels literature, what is often overlooked is how these flows come into existence in the first place. Obviously channel flows do not exist as a force of nature. Rather they must be created. In fact, channel flows are created by people working in all types of marketing institutions all over the world. In effect, channel flows are the ties that bind sellers and buyers and a myriad of intermediaries together to make global commerce possible (Rosenbloom and Larsen 2008).

What implication does the channel flows paradigm hold for modern global channel management? Actually it is a very straightforward and pragmatic one: global marketing requires more efficient and more coordinated channel flows. Fortunately the awesome technology provided by the Internet and worldwide web has made meeting this challenge much more feasible, particularly because with the exception of physical products, all eight channel flows can be implemented via the Internet. Managing the ownership, promotion, negotiation, financing, risk, ordering and payment flows mainly via the Internet is commonplace today in both businessto-consumer (B2C) and business-to-business (B2B markets). Only the physical product flow cannot be digitized into electrons to move over the Internet at the speed of light. Instead, physical products must still be moved, handled and stored using conventional, 'old fashioned' devises such as airplanes, trucks, forklifts, conveyor belts, bricks and mortar warehouses and storage depots (Rosenbloom 2002). Consequently, channel managers seeking better and more coordinated global channel flows by harnessing the power of the Internet will need to pay special attention to the limitations of the Internet as well as its great potential. The demise of so many dot.com firms less than a decade ago can be traced in large part to ignoring the limitations of the Internet in the case of physical products. 


\section{Discrepancy of Assortment Paradigm}

Products are grouped for manufacturing purposes based on efficiencies of production while consumers group products based on convenience of shopping and use. This paradigm was described over a half century ago by a leading marketing scholar as the discrepancy of assortment (Alderson 1954). This discrepancy of assortment is still relevant today. Indeed, the great heterogeneity of supply and enormous diversity of demand across global markets has exacerbated the discrepancy of assortment. Literally millions of different goods are produced from hundreds of countries around the globe to satisfy the enormous diversity of needs and wants of billions of consumers worldwide. Somehow, this vast conglomeration of products must be sorted out and converted into relevant assortments that consumers are seeking. The technologies and institutions that comprise global marketing channels are charged with the challenge of overcoming the discrepancy of assortment.

Thanks to the power of the Internet and the worldwide web, this challenge has been addressed in recent years (Quelch and Klein 1996). Consumers with access to the Internet, can search for products and services from around the world with a few clicks of a mouse and then group those products or services into categories and specific assortments of their own choosing. Has the powerful online technology that enables consumers to access myriad products and then distill out a unique assortment based on their own tastes and preferences eliminated the challenges presented by the discrepancy in assortment paradigm? The 'jury' is still out on this question. Clearly the Internet has enabled online shoppers to easily and efficiently shop from a vast array of products in the global marketplace that would have been inconceivable without this technology. On the other hand, much can still be done in conventional channels to provide consumers with product mixes or assortments that are congruent with their needs and wants. Channel managers at all levels should still think about and strive to improve assortment convenience available to consumers. Indeed, in some cases the careful editing of product assortments in the spirit of 'less is more' may actually enhance the customer experience by simplifying the consumer choice process. Such editing of product assortments to reduce product proliferation has, in recent years, become a major product strategy pursued by some of the world's largest manufacturers such as Procter and Gamble. Channel strategy can augment such efforts if distributors and retailers, both online and conventional, think in terms of assembling relevant rather than merely large product assortments.

\section{Channel Conflict Paradigm}

Although the implicit or explicit paradigm underlying relationships within and across distribution channel is cooperation, conflict is a common, indeed inherent paradigm as well for channel relationships (Stern and Gorman 1969). The reason for this is a very basic human one: When people relate to each other in any kind of 
organization including a channel of distribution, at some point, one or more of the parties will engage in behaviour that impedes the other party's goals. This is the essence of conflict. So, for example, if a retailer heavily promotes its own private brand products and ignores or even disparages the manufacturer's brand, the manufacturer may feel that the retailer is impeding the attainment of the manufacturer's sales goals. This is a typical example of conflict within the distribution channel. Cross channel conflict occurs when different channel structures clash. A common example of this is when a manufacturer uses its direct online channel to reach the same consumers being served by independent retailers carrying the manufacturers products. In this case, the cross channel conflict is between the manufacturer's direct online channel and the indirect retail channel (Rosenbloom 2007).

In general, channel conflict whether within or across channels is viewed as a negative phenomenon in the sense that it reduces channel efficiency. In some instances, however, conflict can be a positive force if it fosters a more optimum allocation of distribution tasks among channel members. But this outcome is likely to be rare (Rosenbloom 1973). More typically, channel managers seek to mitigate conflicts once they arise or attempt to avoid conflict as much as possible.

The wide scope of distribution channels associated with global markets has not changed the basic dynamics of conflict within and across distribution channels. On the contrary, the different backgrounds and cultures of channel members at the distributor and retailer levels in different countries has increased the potential for conflict. Moreover, with the arrival of online channels as a channel option for many firms to reach their customers directly, the potential for cross channel conflict has been magnified. Consequently, channel managers will need to pay even more attention to the channel conflict paradigm. While, channel conflict being an inherent behavioural dimension associated with distribution channels cannot be eliminated, it can be managed. Such management of channel conflict should occur at two levels: 1) during the design stage and 2) during the administration of existing channels.

Channel Design and Conflict Management. The design of global distribution channels is a complex process involving several stages of planning and analysis as well as the consideration of numerous variables that can affect the channel such as the nature of the market segments being targeted, the types of products being marketed, the availability of intermediaries and numerous others (Rosenbloom 2004). One of these 'other' variables is the possible emergence of conflict within the channel or in the case of a multi-channel design, across channels. Consequently, managers responsible for designing global distribution channels need to consider the issue of conflict as an integral part of the channel design process and try to develop channel strategy and structure that will reduce the emergence of conflict or mitigate its effects. For example, if the firm plans to use both direct online channels as well as independent intermediaries to sell its products in overseas markets, a channel strategy that minimizes territorial overlap can reduce the potential for conflict. Or, if both channels will be distributing products in the same territories, a commission scheme that shares revenues from online sales with independent distributors can go a long way toward mitigating cross channel conflict. 
Managing Conflict in Existing Channels. When channels have already been designed with the basic channel structure in place, and no basic channel restructuring is planned, channel managers do not have the option of 'designing out' channel conflict through changes in channel structure, at least not in the short run.. Therefore, conflict has to be dealt with in the normal course of channel management. Essentially this involves three stages or phases: 1) detecting conflict, 2) appraising the effects of conflict, and 3) resolving the conflict.

With regard to detecting conflict, the emergence of channel conflict is not always obvious. It can be more subtle and hidden. The channel manager must therefore be vigilant to detect channel conflict before it becomes a major problem. In global channels where distances are great and multiple channels can be long and complex, the challenge of spotting conflict early is greater. Formal surveys and audits of channel members may be needed to detect conflict at an early stage (Rosenbloom 2004).

With regard to appraising the effects of channel conflict, the channel manager needs to make an assessment as to whether the conflict is likely to have a negative impact on the firm's distribution objectives. If so, some action will need to be planned and implemented to address the conflict.

Finally, options for resolving conflict can range from informal meetings between the parties to the conflict, perhaps over lunch, all the way to bringing legal action seeking resolution through the courts (Dant and Schul 1992). Obviously, and hopefully, early detection of channel conflict and a realistic plan for dealing with the conflict will forestall the need to pursue the more extreme option of taking legal action.

\section{Channel Power Paradigm}

Power has always played a core role in relationships in distribution channels (Brier and Stern 1969). When one channel member seeks to get another channel member to take an action that it otherwise would not have pursued, power has been exercised in the channel. Over the past four decades, marketing channels researchers have examined power in distribution channels extensively. The five bases of power, usually identified as reward, coercion, legitimate, reference, and expertise have all received considerable attention with a particular focus on the adverse effects associated with the use of coercive power (Lusch and Ross 1985). Some general findings emerging from this research are:

- In order to influence channel member behavior, some form of power must be exercised. Therefore, the use of power in the channel is inevitable and pervasive.

- The effectiveness of various power bases in influencing channel member behaviour is situation specific.

- How power is used in the channel can affect the degree of cooperation and conflict in the channel as well as channel member satisfaction. 
- Coercive power tends to foster conflict and channel member dissatisfaction to a greater degree than other power bases (Rosenbloom 2004: 137).

Clearly, channel managers operating in global markets cannot ignore the channel power paradigm. As a practical matter, the capacity to manage global channels effectively depends to a large degree on how skilfully the channel manager is able to exercise power to influence the behaviour of channel members whether they be distributors, dealers, franchisees or various agents and brokers. While practicing channel managers cannot be expected to be intimately familiar with the vast amount of research on power that has appeared in the academic literature in recent decades, they can consult textbooks and mainstream business literature that deal with power in channels of distribution. But even if channel managers do not read any of the formal literature on this subject, an awareness of the pervasiveness of power in distribution channels and the need to exercise power judiciously can be of considerable help. For example, although the 'shortest distance between two points' may appear to be through the use of coercive power such as by a large channel member directing a smaller channel member 'to do something or else,' the negative consequences resulting from exercising power in this fashion could undermine the viability of the relationship between channel members. Moreover, the use of coercive power by a large channel member to dominate smaller channel members can lead to the smaller channel members banding together to attain countervailing power via the legal system.

Thus, if those responsible for managing global channels have an appreciation for the importance of using power judiciously rather than expediently or carelessly, they will have learned the main lesson associated with the channel power paradigm: power in a channel of distribution is a key management tool but one that has to be used with great care.

\section{Conclusion}

The six channel concepts or paradigms discussed in this article that have appeared in the marketing channels literature for decades still provide insight for managing today's global marketing channels. Distribution channel paradigms concerning disintermediation, functional shifting, channel flows, discrepancy in assortment, conflict, and power, all have something to offer channel managers responsible for designing and managing global channel structures and multichannel structures to make products and services conveniently available all over the world.

Disintermediation, perhaps the oldest and most controversial channel paradigm, reminds the channel manager that the existence of middlemen or intermediaries in channels of distribution is, as always, dependent on how efficiently they perform distribution services.

The related distribution channel paradigm of functional shifting also alerts channel managers to the fact that functions or distribution tasks cannot be eliminated - only shifted or reallocated to those parties in the channel that can perform the most effectively and efficiently. The basic determinant of how this 
functional shifting or allocation should occur in today's high-tech and global channel systems is still based on the key factors of cost, desire for control, and core competency.

The channel flows paradigm, an important but often forgotten concept, can help channel managers grasp both the potential and limitations of Internet-based online channels in today's global markets. The ability to digitize flows provides channel managers with tremendous opportunities to increase channel effectiveness and efficiency. But, the physical product flow also reminds channel managers that a huge array of real and tangible products must still flow through channels by conventional means instead of the Internet.

The paradigm referred to as discrepancy of assortment has been magnified by the vast and heterogeneous global markets in which marketing channels operate today. However, relatively recent technological breakthroughs, especially the rapid development of Internet-based electronic commerce has provided the technological means to drastically improve the sorting out process to overcome the discrepancy of assortment. Still, much remains to be done, especially in conventional channels to create convenient and efficient assortments on both the demand and supply sides of global distribution channels.

Conflict which has always been present within and across distribution channels has been exacerbated in recent years by the diversity of cultures represented in global marketing channels as well as the emphasis on multi-channel marketing which tends to increase cross channel conflict. Thus, channel managers will need to pay more attention then ever to 'designing out' conflict when developing new global channel structures and to detecting conflict, appraising its possible negative effects, and resolving conflict as an integral part of channel management.

Finally the channel power paradigm serves to continually remind the channel manager that the use of power in the channel is inescapable. Indeed, the management of international channels to reach distant markets around the globe increases the need to exercise power to accomplish distribution objectives. So clearly, power in the channel of distribution is a key management tool but one that has to be used with great care.

\section{Bibliography}

Alderson Wroe, Factors Governing the Development of Marketing Channels, Richard M. Clewett (ed.), Marketing Channels for Manufactured Products, Richard D. Irwin, Homewood, IL, 1954, pp. 5-22.

Anderson Philip, Anderson Erin, The New E-Commerce Intermediaries, Sloan Management Review, Summer 2002, pp. 53-62.

Beckman T.N., Engle N.H., Buzzell R.D., Wholesaling, Ronald Press, New York, 1959.

Cateora, P.R., Graham J.L., International Marketing, McGraw-Hill Irwin, Boston, 2007.

Czinkota Michael R., Ronkainen IIkka A., Tarrant John J., The Global Marketing Imperative, NTC Business Books, Lincolnwood, IL, 1995.

Dant M., Rajiv P., Schul Patrick L., Conflict Resolution Processes in Contractual Channels of Distribution, Journal of Marketing, January 1992, pp.38-54.

http://dx.doi.org/10.2307/1252131 
Kalakota Ravi, Whinston Andrew B., Electronic Commerce, Addison-Wesley, Reading Massachusetts, 1996.

http://dx.doi.org/10.1109/TCPMC.1996.507151

Little Robert W., The Marketing Channel: Who Should Lead This Extra-Corporate Organization?, Journal of Marketing, January, 1970, pp.31-38. http://dx.doi.org/10.2307/1250293

Lusch Robert F., Ross Robert H., The Nature of Power in a Marketing Channel, Journal of the Academy of Marketing Science, Summer, 1985, pp. 39-56.

http://dx.doi.org/10.1007/BF02729935

Mallen Bruce, Functional Spin-Off: A Key to Anticipating Change in Distribution Structure, Journal of Marketing, July, 1973, pp. 18-25. http://dx.doi.org/10.2307/1249942

Prahalad C.K., Hamel Gary, The Core Competence of the Corporation, Harvard Business Review, May-June 1990, pp. 79-91.

Quelch John A., Klein Lisa R., The Internet and International Marketing, Sloan Management Review, Spring 1996, pp. 60-75.

Rosenbloom Bert, Conflict and Channel Efficiency: Some Conceptual Models for the Decision Maker, Journal of Marketing, July 1973, pp. 26-30.

Rosenbloom Bert, The Ten Deadly Myths of E-Commerce, Business Horizons, March-April 2002, pp. 61-66. http://dx.doi.org/10.1016/S0007-6813(02)00189-1

Rosenbloom Bert, Marketing Channels: A management View, $7^{\text {th }}$ edition, Thomson/South Western, Mason, Ohio, 2004.

Rosenbloom Bert, Multi-Channel Strategy in Business-to-Business Markets: Prospects and Problems, Industrial Marketing Management, January 2007, pp.4-9. http://dx.doi.org/10.1016/j.indmarman.2006.06.010

Rosenbloom Bert, Larsen Trina, Wholesalers as Global Marketers, Journal of Marketing Channels, vol. 15, n. 1, 2008, pp. 235-252. http://dx.doi.org/10.1080/10466690802063879

Stern Louis W., Gorman Ronald H., Conflict in distribution Channels: An Exploration, Stern Louis W. (ed.), Distribution Channels: Behavioral Dimensions, Houghton Mifflin Company, Boston, 1969, pp. 156-175.

Stigler George, The Division of Labor is Limited by the Extent of the Market, Journal of Political Economy, June 1951, pp. 185-193. http://dx.doi.org/10.1086/257075

Vaile Roland S., Grether E.T., Cox Revis, Marketing in the American Economy, Ronald Press, New York, 1952, pp. 113-129.

Weld L.D.H., Marketing Functions and Mercantile Organization, American Economic Review, June 1917, pp. 306-318. 